\title{
Peripheral tuberculous lymphadenitis in pediatrics: 16 years of experience in a tertiary care pediatric hospital of Buenos Aires, Argentina
}

\author{
Silvina E. Neyro, M.D. ${ }^{a}$, Isabel R. Squassi, M.D. ${ }^{a}$, Martín Medín, M.D. ${ }^{b}$ \\ Ana Caratozzolo, Biochemist ${ }^{c}$, Andrés Martinez Burkett, M.D. ${ }^{d}$ and \\ María C. Cerqueiro, M.D. ${ }^{a}$
}

\begin{abstract}
Extrapulmonary tuberculosis accounts for $15-20 \%$ of all clinical presentations of tuberculosis. Peripheral tuberculous lymphadenitis is the second most common presentation of extrapulmonary tuberculosis in children, after pleural tuberculosis, in Argentina.

We analyzed 92 patients with peripheral tuberculous lymphadenitis seen at the Department of Tisiology of Hospital de Niños "Dr. Ricardo Gutiérrez" between August 2000 and September 2015. The patients' mean age was $8.7 \pm 5$ years. Nodal sites corresponded to single peripheral $(31.5 \%)$, multiple peripheral $(20.6 \%)$, and peripheral associated with deep nodes $(47.8 \%)$. Cervical lymph nodes were the most common site of involvement (80\%). In $80 \%$ of patients previous antibiotic therapy had been administered, without response. The tuberculosis source was known in $56 \% ; 69 \%$ had a positive tuberculin skin test; and $54 \%$, a pathological chest X-ray. Tuberculosis treatment was started on all patients based on clinical criteria, exposure and/or positive tuberculin skin test, prior to microbiological or histological confirmation. The clinical course was either healing $(81.5 \%)$, referral to a facility near home $(8.7 \%)$ or dropout $(8.7 \%)$. One patient died.
\end{abstract}

Key words: Mycobacterium tuberculosis, tuberculous lymphadenitis, peripheral lymphadenopathy, child, pediatrics.

Tisiology.

b. Department of Anatomic Pathology.

c. Molecular Biology Laboratory.

d. Division of Dermatology. Hospital de Niños "Ricardo Gutiérrez." Autonomous City of Buenos Aires.

E-mail address: Silvina E. Neyro, M.D.: silvinaneyro@gmail.com

Funding:

None.

Conflict of interest: None.

Received: 12-22-2017 Accepted: 5-16-2018 http:/ / dx.doi.org/10.5546/ aap.2018.eng.430

To cite: Neyro SE, Squassi IR, Medín M, Caratozzolo A, et al. Peripheral tuberculous lymphadenitis in pediatrics: 16 years of experience in a tertiary care pediatric hospital of Buenos Aires, Argentina. Arch Argent Pediatr 2018;116(6):430-436.

\section{INTRODUCTION}

Tuberculosis is a major public health problem worldwide. It is one of the main causes of infectious disease and mortality, especially in developing countries, and has been recognized as one of the top 10 causes of death worldwide by the World Health Organization (WHO) ${ }^{1}$
Although the fight against tuberculosis has progressed significantly -43 million lives have been saved since 2000 thanks to the efforts made to optimize diagnosis and treatment- the battle is far from being won because more than 4000 people die due to tuberculosis every day worldwide. It has been estimated that, in 2015, 1 million children fell ill with tuberculosis and 170000 children died (excluding children living with human immunodeficiency virus [HIV]). ${ }^{2}$

In Argentina, 9761 cases of tuberculosis (new and relapse cases) were diagnosed in 2015 (22.6 cases / 100000 inhabitants), 156 cases more than in 2014. Although the national occurrence of tuberculosis among children and adolescents has decreased, the jurisdictional trend has been inconsistent. A reduction is observed when comparing the number of tuberculosis cases reported between 1990 and 2015 in children younger than 9 years. However, the practically stable trend of cases reported in adolescents aged 15 to 19 years in the past 16 years is alarming and requires the strengthening of control measures. ${ }^{3}$

Extrapulmonary tuberculosis accounts for approximately 15-20\% of all clinical presentations of tuberculosis. ${ }^{4,5}$ Peripheral tuberculous lymphadenitis (PTL) is, in turn, one of the most common presentations of extrapulmonary tuberculosis in pediatrics in Argentina, after pleural tuberculosis. ${ }^{3}$ It may or may not be accompanied by concomitant active pulmonary involvement. Traditionally, cervical lymphadenitis has been the most common site (60-80 \%), formerly 
known as "scrofula." However, other lymph node groups may be affected. ${ }^{5}$ Given the varied differential diagnoses of lymphadenopathies in pediatrics and/or the absence of an early clinical suspicion, PTL is an ongoing challenge for a timely diagnosis and management.

To our knowledge, this is the first case study published on PTL in the field of pediatrics in Argentina in recent years. The objective of this study was to assess PTL cases diagnosed in our Department by addressing the patients' demographic, epidemiological, clinical, diagnostic, therapeutic, and evolutionary characteristics.

\section{POPULATION AND METHODS}

This was a retrospective and descriptive study of PTL cases seen at the Department of Tisiology of Hospital de Niños "Dr. Ricardo Gutiérrez" (a tertiary care pediatric hospital of the Autonomous City of Buenos Aires, Argentina) carried out between August 2000 and September 2015.

The following characteristics were obtained from the medical records of patients with a confirmed or suspected diagnosis of PTL: demographic, clinical (comorbidities, signs and symptoms, presentation), epidemiological (source of transmission), diagnostic (lab tests, tuberculin skin test, microbiological and imaging tests), therapeutic (time until treatment, safety), and evolutionary (healing, dropout or death), and entered into an ad hoc database. The Epi Info $7^{\circledR}$ software was used for statistical analysis. Continuous outcome measures were reported as mean or median and range. Categorical outcome measures were expressed in number and percentage.
The present study was evaluated and approved by the Hospital Ethics Committee.

\section{RESULTS}

In the studied period, a total of 1607 tuberculosis pediatric patients were diagnosed, followed-up, and treated (average: 100.4 cases per year). Extrapulmonary involvement was observed in $24 \%$ of patients (381 cases). Of these, $92 \mathrm{had}$ PTL, which accounted for $24 \%$ of extrapulmonary tuberculosis cases and for $6 \%$ of all tuberculosis cases. Based on the distribution of cases per year in the study period, $51 \%(47 / 92)$ occurred in the past 5 years (2011-2015) (Figure 1).

The analysis of demographic data of these 92 PTL cases is shown in Table 1. The patients' mean age at the time of onset was $8.7 \pm 5$ years; $42.4 \%$ of all children were in the older than 10 years-old age group (Figure 2). Only 1 patient was older than 18 years; he had been receiving multidisciplinary follow-up in our hospital since childhood for systemic lupus erythematosus. Female patients predominated and were affected at an older age compared to boys (female patients' mean age: 10 years versus male patients' mean age: 7 years; $p<0.04)$. Fifty-nine percent of cases occurred in children without preexisting and/or associated diseases .

Single-peripheral and multiple-peripheral lymphadenopathies were observed in $31.5 \%$ and $20.6 \%$ of cases (29/92 and 19/92, respectively); $47.8 \%(44 / 92)$ had an associated deep lymphadenopathy. In relation to the nodal site, cervical lymphadenopathies predominated $(80 \%)$, followed by facial $(12 \%)$, axillary $(11 \%)$, supraclavicular $(8 \%)$, and inguinal (5\%) lymphadenopathies.

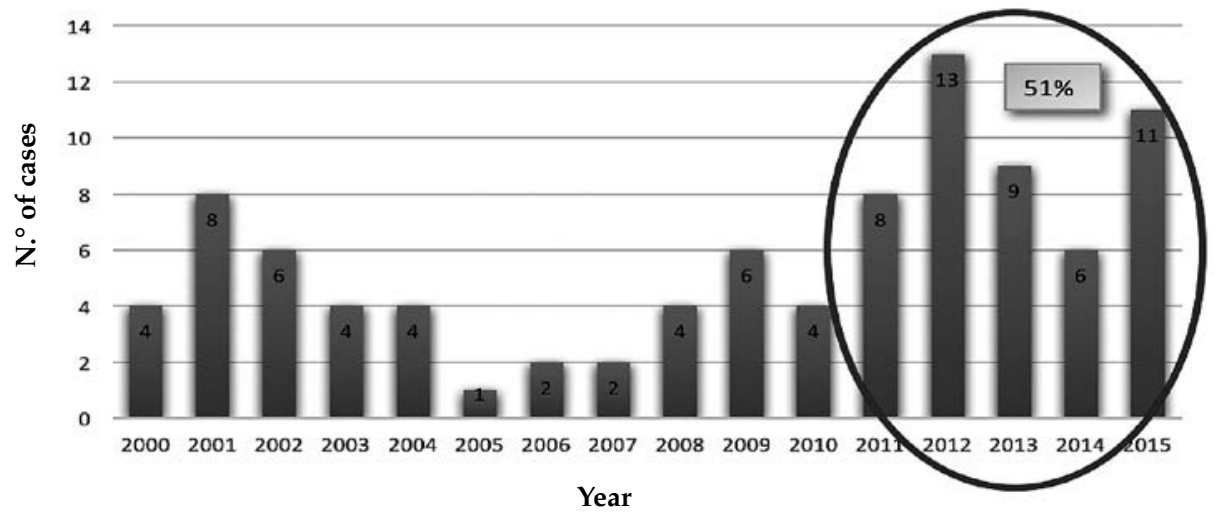


At the time of the visit to the hospital, $49 \%$ (45/92) of patients had subacute or chronic lymphadenopathy, without accompanying signs or symptoms. Other signs and symptoms, such as fever, respiratory distress, bacillary impregnation, and weight loss, were observed in some patients (Figure 3). Antibiotic therapy had been administered, without clinical response, to $80 \%$ of patients for common microorganisms before referral to or consultation at our hospital.

In relation to diagnosis, only $56 \%$ of patients had a known source of transmission, which was more frequently identified at a younger age (mean age of patients with a known source: 7 years versus unknown/suspected source of transmission: 11 years; $\mathrm{p}<0.006)$. All patients

TABLE 1. Demographic characteristics and comorbidities of the studied population. $N=92$

\begin{tabular}{|c|c|c|c|}
\hline \multicolumn{2}{|c|}{ Demographic characteristics } & n $(\%)$ & Mean (range $[r]$ ) \\
\hline \multicolumn{3}{|c|}{ Age (years) } & 8.7 (r: 2 months-23 years) \\
\hline \multicolumn{4}{|l|}{ Sex } \\
\hline & Female & $53(57.6 \%)$ & \\
\hline & Male & $39(42.4 \%)$ & \\
\hline \multicolumn{4}{|l|}{ Origin } \\
\hline & Autonomous City of Buenos Aires & $26(28.3 \%)$ & \\
\hline & Province of Buenos Aires & $49(53.3 \%)$ & \\
\hline & Other provinces & $17(18.4 \%)$ & \\
\hline \multicolumn{2}{|c|}{ Living in over-crowding conditions } & $54(58.7 \%)$ & \\
\hline \multicolumn{4}{|c|}{ Comorbidities } \\
\hline \multirow[t]{3}{*}{ Immunosuppression } & Severe malnutrition & $6(6.5 \%)$ & \\
\hline & Cancer & $4(4.4 \%)$ & \\
\hline & Rheumatic disease & $2(2.2 \%)$ & \\
\hline Respiratory disease & & $12(13 \%)$ & \\
\hline Co-infections & & $12(13 \%)$ & \\
\hline Other comorbidities & & $2(2 \%)$ & \\
\hline None & & $54(59 \%)$ & \\
\hline
\end{tabular}

FIGURE 2. Distribution of peripheral tuberculous lymphadenitis patients by age group and sex

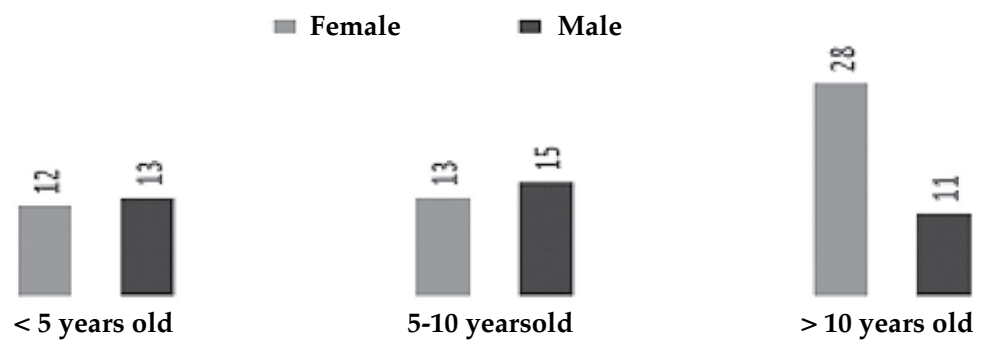

FIGURE 3. Accompanying signs and symptoms of subacute and chronic lymphadenopathy

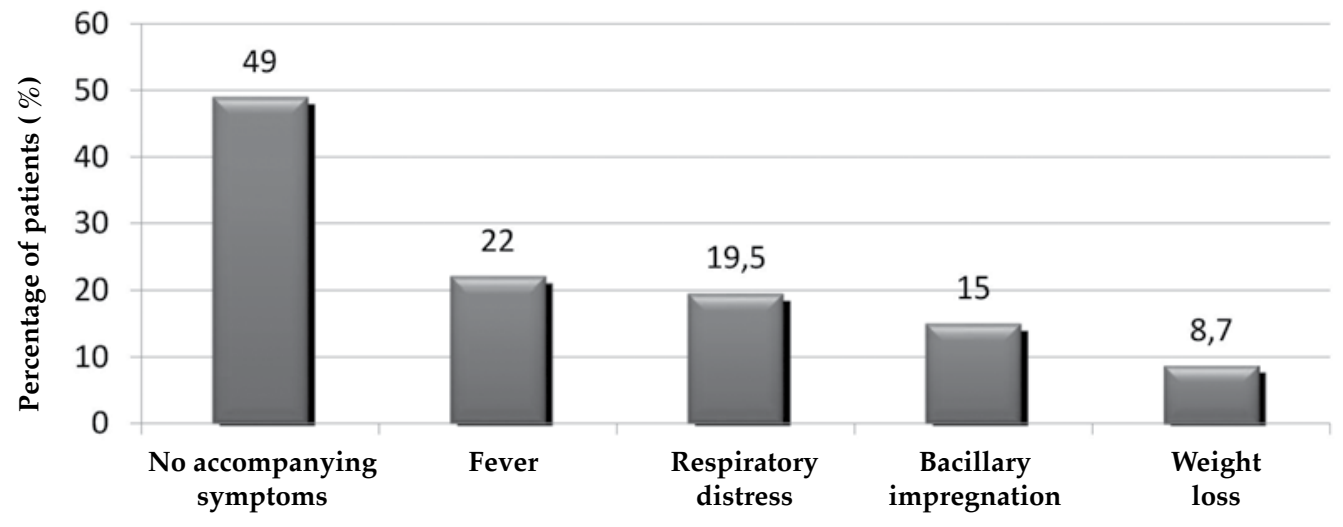


had received the Bacillus Calmette-Guerin (BCG) vaccine. The tuberculin skin test (purified protein derivative, $\mathrm{PPD}$ ) was positive in $69 \%$ and negative in $31 \%$ of cases. A pathological chest X-ray was observed in $54 \%$ of patients (the most common radiological patterns were hilar and mediastinal lymphadenopathy and pneumonia). Laboratory findings were non-specific (e.g., mean white blood cell count: 9440 cells $/ \mathrm{mm}^{3}$ \pm 4600 , mean erythrocyte sedimentation rate: $45 \mathrm{~mm} / \mathrm{h} \pm 32$ ). The ultrasound was useful to monitor the progress of the lesion and to determine accessibility for surgical procedures in 70 patients $(76 \%)$.

Besides, $63 \%$ (58/92) of patients required hospitalization (due to the severity of their condition or to perform tests) for a mean of 14 days. The length of hospitalization was more prolonged among immunocompromised hosts (mean of 39 days, $\mathrm{p}<0.001$ ) and among patients with a pulmonary source of infection (mean of 25 days, $p<0.001$ ) and those with adverse reactions to anti-tuberculosis drugs (mean of 25 days, $\mathrm{p}<0.01)$.

A total of $84 / 92(91 \%)$ patients were tested for tuberculosis, using either lymph node and/ or respiratory secretion samples for a direct test, a culture, a traditional polymerase chain reaction (PCR) using IS6110 primers, or histology testing. Seventy-seven diagnostic surgeries were performed in the lymph nodes: $26 / 92$ by fineneedle aspiration biopsy (FNAB), 46/92 by biopsy, and $5 / 92$ by resection. Microbiological diagnosis was confirmed in $60 \%$ of all samples (respiratory secretion and/or lymph node samples) using a culture and in $64.7 \%$ of samples analyzed by PCR (Table 2). All positive cultures corresponded to Mycobacterium tuberculosis susceptible to first-line drugs. Diagnostic tests were not done in 8 patients due to missing respiratory secretion samples and/or the hospital's inability to perform the diagnostic surgery immediately; however, all of them had a favorable response to the administered empirical therapy.

All patients were started on therapy ( 3 or 4 first-line tuberculosis agents administered orally: isoniazid, rifampicin, pyrazinamide, with or without ethambutol) for a compatible clinical condition, positive exposure and/or PPD test, before microbiological or histological confirmation. The mean time of lymphadenopathy progression at the time of anti-tuberculosis treatment initiation was 82 days \pm 70.5 days (longer among immunocompetent children $[\mathrm{p}<0.05]$ and multiple lymphadenopathies $[p<0.02])$. Adverse reactions to anti-tuberculosis agents were observed in $19.5 \%$ of patients; hepatitis was the most common finding $(9 / 18)$.

The clinical course was favorable -healing-in $81.5 \%$ of cases. During the course of treatment, $8.7 \%$ of patients were referred to a facility near their home to complete it. Another $8.7 \%$ dropped out from treatment. Only 1 patient died, who had been diagnosed with concomitant lymphoproliferative syndrome. Based on clinical criteria and due to the high epidemiological risk, treatment continued empirically in 26 patients; $81 \%$ had a favorable response.

TABLE 2. Percentage of positive results for Mycobacterium tuberculosis, based on the analyzed sample

\begin{tabular}{|c|c|}
\hline $\begin{array}{l}\text { Tests conducted in lymph node } \\
\text { and/or respiratory secretion samples }\end{array}$ & $\begin{array}{c}\text { Positive samples/total analyzed samples } \\
\text { ( } \% \text { of positive results) }\end{array}$ \\
\hline Direct test (sputum smear) & $\begin{array}{c}7 / 84(8.3 \%) \\
\text { The } 7 \text { positive samples corresponded to } 4 \text { lymph } \\
\text { node samples and } 3 \text { respiratory secretion samples. }\end{array}$ \\
\hline Culture & $\begin{array}{l}\qquad 42 / 60(60 \%) \\
\text { The } 42 \text { positive samples corresponded to } 21 \text { lymph node samples, } \\
6 \text { respiratory secretion samples, } \\
\text { and } 15 \text { respiratory secretion + lymph node samples. }\end{array}$ \\
\hline PCR & $\begin{array}{l}22 / 34(64.7 \%) \\
\text { The } 22 \text { positive samples corresponded to } 15 \text { lymph node samples, } \\
3 \text { respiratory secretion samples, and } 4 \text { lymph node }+ \\
\text { respiratory secretion samples. }\end{array}$ \\
\hline Histology & $45 / 51(88.2 \%)$ \\
\hline
\end{tabular}

PCR: polymerase chain reaction 


\section{DISCUSSION}

Our study covered 16 years of pediatric tuberculous lymphadenitis cases. This presentation of extrapulmonary tuberculosis was the second most common one, after pleural tuberculosis, during the entire study period; however, other studies reported it as the leading clinical presentation of extrapulmonary tuberculosis in other countries. ${ }^{6,7}$

Peripheral tuberculous lymphadenitis may occur in the context of a primary infection (as seen in young children and/or immunocompromised patients) or may indicate a reactivation of a prior primary infection. The epidemiology of PTL varies between developed and developing countries. In developed countries, most PTL cases occur among adult immigrants from countries where tuberculosis is endemic ${ }^{8,9}$ and show a pattern that is consistent with disease reactivation. This was documented in PTL case series in countries such as France and Germany, where approximately $70 \%$ of cases were observed among immigrants. ${ }^{8,9}$ Although PTL has been traditionally considered a childhood disease, in recent years, the maximum age of onset in developed countries has shifted from childhood to young adulthood (20-40 years old). ${ }^{8,10}$

As in most published series, it has been evidenced that PTL was more common among women, ${ }^{7,11}$ which is different from the pulmonary tuberculosis pattern, which is more frequent among men. ${ }^{12}$

The cervical-facial region was the most common site for lymphadenopathies, similar to other publications. ${ }^{5}$ These are usually painless, slowly progressing lymphadenopathies. ${ }^{13}$ Spontaneous drainage has been described in $4-11 \%$ of cases. ${ }^{13,14}$ Systemic signs and symptoms may not be present, although they were reported in up to $55 \%$ of tuberculous lymphadenitis cases ${ }^{15}$ and should be taken into consideration during history-taking. In our study, $51 \%$ of cases had an accompanying sign or symptom.

The PPD was positive in $69 \%$ of our patients. A study conducted by A. Polesky et al. in the United States evidenced a positive tuberculin skin test in 90 out of $92(98 \%)$ immunocompetent patients with tuberculous lymphadenitis. ${ }^{16} \mathrm{In}$ studies carried out on lymphadenitis in South Korea and India, the PPD sensitivity was $86 \%$ and $89 \%$, respectively. ${ }^{17,18}$

Radiological alterations compatible with hilar and mediastinal lymphadenopathies or pulmonary lesions were detected in $54 \%$ of our patients, higher than what has been reported in other series. ${ }^{19,20}$ The presence of a pulmonary lesion was inconsistent across the different publications: M. S. Kamal et al. reported it in only $3.1 \%$ of cases; ${ }^{11} \mathrm{~B}$. C. Jha et al. and P. B. Magsi et al., described it in $16 \%$ and $7.5 \%$, respectively. ${ }^{21,22}$ However, the study by N. Choudhury et al. evidenced pulmonary involvement in $48 \%$ of cases ${ }^{23}$ which is more similar to our findings.

In our series, the delay in diagnosis and management was attributed to a low clinical and epidemiological suspicion index because symptoms were mostly interpreted as pyogenic lymphadenitis, leaving aside the absence of response to antibiotics or a history of a known source of transmission, an essential epidemiological factor for diagnostic suspicion. ${ }^{24}$

In relation to the etiologic agent, $M$. bovis has been historically a frequent microorganism in chronic lymphadenitis; however, milk pasteurization and bovine tuberculosis management have practically ruled out this source of human infection in developed countries. Although, at present, $M$. tuberculosis is the most common cause of tuberculous lymphadenitis, ${ }^{25}$ unpasteurized milk is still a risk factor to be taken into consideration. ${ }^{26}$

Sample collection for microbiological and pathology testing using FNAB and/or lymph node biopsy is critical to confirm diagnosis. FNAB has been proposed, in recent years, as a firstline diagnostic technique, especially in endemic countries, where it has demonstrated sensitivity and specificity..$^{27,28}$ This procedure offers several advantages. The most important ones are that it is safe and cost-effective, may be done in the outpatient setting, is less invasive and more accessible than a biopsy, especially in limited resource countries. ${ }^{29}$

The definitive diagnosis of tuberculous lymphadenitis may be done using a culture or PCR to check for the presence of $M$. tuberculosis in the sample collected from an affected lymph node. A culture is still the gold standard for diagnosis; however, results may take weeks. The histological characteristics (e.g., caseating granulomas) are highly suggestive and strongly support the diagnosis in patients with compatible clinical criteria and positive epidemiological findings for tuberculosis, especially in the field of pediatrics because this population usually has paucibacillary lesions. In our study, histopathology played a major diagnostic role; 
most of the analyzed samples showed findings compatible with tuberculosis.

Antibiotic therapy with anti-tuberculosis agents is still the cornerstone of tuberculous lymphadenitis management, although response may be slow and even paradoxical in up to $20 \%$ of cases (existing lymphadenopathy enlargement or new lymphadenopathy during effective treatment, and even after it). ${ }^{16,30,31}$ Usually, a 6-month treatment is enough for healing in the case of bacilli susceptible to first-line drugs. This recommendation is based on studies that showed no significant differences between 6- and 9-month treatments in terms of healing $(89 \%-94 \%)^{32,33}$ or relapse $(3 \%){ }^{34}$

The Infectious Diseases Society of America Clinical Practice Guidelines do not recommend therapeutic lymph node resection, except in unusual circumstances. ${ }^{35}$ In our study, lymph node resection was done in 5 patients; however, their clinical course was not affected due to this procedure.

The strength of this study is that it provides data in relation to the follow-up of a significant number of PTL cases over a prolonged period in a single facility. Notwithstanding, it has weaknesses inherent to a retrospective case study.

\section{CONCLUSIONS}

A higher degree of tuberculosis suspicion is necessary when children present with lymphadenopathy, especially in the case of a subacute or chronic status, in the absence of response to the regular antibiotic therapy or in the case of a known source of transmission, which is an essential epidemiological factor that should be taken into consideration in this situation.

An optimal timely sample collection is critical given the high diagnostic confirmation that may result from an adequate case analysis.

PTL has a good prognosis, even after a delayed diagnosis, with a high healing rate.

\section{REFERENCES}

1. World Health Organization. Tuberculosis. [Accessed on: January 31st, 2017]. Available at: http:/ / www.who.int/ mediacentre/factsheets/fs104/en/.

2. World Health Organization. Global Tuberculosis Report 2016. [Accessed on: February 1st, 2017]. Available at: http:/ / www.who.int/tb/publications/global_report/en/.

3. Instituto Nacional de Enfermedades Respiratorias "Dr. Emilio Coni". Notificación de casos de tuberculosis en la República Argentina, período 1980-2015. Santa Fe: Ministerio de Salud - ANLIS; 2016. [Accessed on: February 3rd, 2017]. Available at: http: / / www.anlis.gov. ar/iner/wp-content / uploads / 2016/11/ Notificacion-
de-casos-de-Tuberculosis-en-la-Republica-ArgentinaPeriodo-1980-2015.pdf.

4. Comité Nacional de Neumonología; Comité Nacional de Infectología. Criterios de diagnóstico y tratamiento de la tuberculosis infantil. Resumen ejecutivo. Arch Argent Pediatr 2016; 114(2):189-90.

5. Mohapatra PR, Janmeja AK. Tuberculous Lymphadenitis. J Assoc Physicians India 2009; 57:585-90.

6. Nelson L, Schneider E, Wells Ch, et al. Epidemiology of childhood tuberculosis in the United States, 1993-2001: The need for continued vigilance. Pediatrics 2004; 114(2):33341.

7. Handa U, Mundi I, Mohan S. Nodal tuberculosis revisited: a review. J Infect Dev Ctries 2012; 6(1):6-12.

8. Geldmacher H, Taube C, Kroeger C, et al. Assessment of lymph node tuberculosis in northern Germany: a clinical review. Chest 2002; 121(4):1177-82.

9. Fain O, Lortholary $\mathrm{O}$, Djouab $\mathrm{M}$, et al. Lymph node tuberculosis in the suburbs of Paris: 59 cases in adults not infected by the human immunodeficiency virus. Int J Tuberc Lung Dis 1999; 3(2):162-5.

10. Perlman DC, D'Amico R, Salomon N. Mycobacterial Infections of the Head and Neck. Curr Infect Dis Rep 2001; 3(3):233-41.

11. Kamal MS, Hoque MH, Chowdhury FR, et al. Cervical Tuberculous Lymphadenitis: Clinico-demographic Profiles of Patients in a Secondary Level Hospital of Bangladesh. Pak J Med Sci 2016; 32(3):608-12.

12. Chen YM, Lee PY, Su WJ, et al. Lymph node tuberculosis: 7-year experience in Veterans General hospital, Taipei, Taiwan. Tuber Lung Dis 1992; 73(6):368-71.

13. PurohitMR, Mustafa T, Morkve O, et al. Gender differences in the clinical diagnosis of tuberculous lymphadenitis-a hospital-based study from Central India. Int J Infect Dis 2009; 13(5):600-5.

14. Khan FY. Clinical pattern of tuberculous adenitis in Qatar: experience with 35 patients. Scand J Infect Dis 2009; 41(2):128-34.

15. Penfold CN, Revington PJ. A review of 23 patients with tuberculosis of the head and neck. Br J Oral Maxillofac Surg 1996; 34(6):508-10.

16. Polesky A, Grove W, Bhatia G. Peripheral tuberculous lymphadenitis: epidemiology, diagnosis, treatment, and outcome. Medicine (Baltimore) 2005; 84(6):350-62.

17. Song KH, Jeon JH, Park WB, et al. Usefulness of the wholeblood interferon-gamma release assay for diagnosis of extrapulmonary tuberculosis. Diagn Microbiol Infect Dis 2009; 63(2):182-7.

18. Khan R, Harris SH, Verma AK, et al. Cervical lymphadenopathy: scrofula revisited. J Laryngol Otol 2009; 123(7):764-7.

19. Starke J, Muñoz F. Tuberculosis. In: Berhman R, Kliegman RM, Jenson HB, eds. Nelson Textbook of Pediatrics. 16th ed. London: W. B. Saunders Co; 2000:885-95.

20. Ibekwe AO, al Shareef Z, al Kindy S. Diagnostic problems of tuberculous cervical adenitis (scrofula). Am JOtolaryngol 1997; 18(3):202-5.

21. Jha BC, Dass A, Nagarkar NM, et al. Cervical tuberculous lymphadenopathy: Changing clinical pattern and concepts in management. Postgrad Med J 2001; 77(905):185-7.

22. Magsi PB, Jamro B, Shaikh AA, et al. An audit of 140 cases of cervical lymphadenopathy at tertiary care hospital. Gomal J Med Sci 2013; 11(1):47-9.

23. Choudhury N, Bruch G, Kothari P, et al. 4 years' experience of head and neck tuberculosis in a south London hospital. J R Soc Med 2005; 98(6):267-9.

24. HowieS, Voss L, Baker L, etal. Tuberculosis in New Zealand, 
1992-2001: a resurgence. Arch Dis Child 2005; 90(1):115761.

25. Yates MD, Grange JM. Bacteriological survey of tuberculous lymphadenitis in southeastEngland, 1981-1989.JEpidemiol Community Health 1992; 46(4):332-5.

26. Kazwala RR, Daborn CJ, Sharp JM, et al. Isolation of Mycobacterium bovis from human cases of cervical adenitis in Tanzania: a cause for concern? Int J Tuberc Lung Dis 2001; 5(1):87-91.

27. Ellison E, Lapuerta P, Martin SE. Fine needle aspiration diagnosis of mycobacterial lymphadenitis. Sensitivity and predictive value in the United States. Acta Cytol 1999; 43(2):153-7.

28. Wright CA, van der Burg M, Geiger D, et al. Diagnosing mycobacterial lymphadenitis in children using fine needle aspiration biopsy: cytomorphology, ZN staining and autofluorescence-making more of less. Diagn Cytopathol 2008; 36(4):245-51.

29. Chand P, Dogra R, Chauhan N, et al. Cytopathological Pattern of Tubercular Lymphadenopathy on FNAC: Analysis of 550 Consecutive Cases. J Clin Diagn Res 2014; 8(9):FC16-9.
30. Cho OH, Park KH, Kim T, et al. Paradoxical responses in non-HIV-infected patients with peripheral lymph node tuberculosis. J Infect 2009; 59(1):56-61.

31. Hawkey CR, Yap T, Pereira J, et al. Characterization and management of paradoxical upgrading reactions in HIVuninfected patients with lymph node tuberculosis. Clin Infect Dis 2005; 40(9):1368-71.

32. Campbell IA, Ormerod LP, Friend JA, et al. Six months versus nine months chemotherapy for tuberculosis of lymph nodes: final results. Respir Med 1993; 87(8):621-3.

33. Yuen AP, Wong SH, Tam CM, et al. Prospective randomized study of thrice weekly six-month and nine-month chemotherapy for cervical tuberculous lymphadenopathy. Otolaryngol Head Neck Surg 1997; 116(2):189-92.

34. Van Loenhout-Rooyackers JH, Laheij RJ, Richter C, et al. Shortening the duration of treatment for cervical tuberculous lymphadenitis. Eur Respir J 2000; 15(1):192-5.

35. Nahid P, Dorman SE, Alipanah N, et al. Official American Thoracic Society/Centers for Disease Control and Prevention/Infectious Diseases Society of America Clinical Practice Guidelines: Treatment of Drug-Susceptible Tuberculosis. Clin Infect Dis 2016; 63(7):e147-95. 